\title{
整株麻黄化石的发现及其对麻黄科(尼藤目)形态、 生态和演化的启示
}

\author{
王至全 $^{(2)}$ ，郑少林 ${ }^{(3)}$
}

(1) 中国科学院南京地质古生物研究所, 南京 210008 ;

(2) 深圳市中国科学院仙湖植物园, 深圳 518004;

(3) 中国地质调查局沈阳地质调查中心, 沈阳 110034

E-mail: brandonhuijunwang@gmail.com

2009-08-18 收稿, 2009-09-11 接受

国家自然科学基金(批准号: 40772006, 40372008, 40632010, J0630967)和教育部留学回国人员科研启动基金资助项目

\begin{abstract}
摘要 虽然已有很多关于麻黄科化石的报道, 但是其作为整株植物保存下来的并不多见. 正是 由于对于部分保存的化石材料缺乏信任, 通过 DNA 序列分析来研究麻黄的现代生物学家怀疑 麻黄的早期起源进而提出了麻黄的近代起源说. 为了进一步增进对麻黄植物历史的了解, 报道 了来自辽宁省早白严世义县组整株保存的麻黄化石一一洪涛麻黄(新种). 这些化石具有麻黄的 典型特征, 如灌木习性、交互对生的分支方式、带有珠孔管的顶生雌性单位. 这些整株保存的 化石为麻黄的早白严纪录提供了强有力的支持, 有助于消除目前关于麻黄起源时间的争议, 并 对人们了解麻黄科植物的形态、生活习性、生态和演化有所裨益.

关键词

化石

尼藤目

整株植物

洪涛麻黄

白严纪

辽宁
\end{abstract}

尼藤目之所以是植物学中很有意义的裸子植物 类群, 是因为其在种子植物系学中占有独特的演化 地位. 尽管它和被子植物共有不少特征, 例如木质部 中的导管、结网的叶脉、双受精现象、偶尔的昆虫传 粉 $^{[1 ~ 3]}$, 但是最近的分子证据认为它是松科相近 ${ }^{[4]}$. 新近的研究认为, 其实形态学和分子证据的冲突并 不太大, 尼藤类可以同样简约地分别与生花植物和 松柏类相关联 ${ }^{[5]}$. 尼藤目可以分为 3 个相当独立的科, 即麻黄科、尼藤科和百岁兰科 ${ }^{[6,7]}$. 这些植物虽然现 在并不繁盛, 但是它们在早白严世却兴盛一时 ${ }^{[8 \sim 6]}$. Drewria potomacensis 是一种产自北美东海岸早白严 世的保存良好的尼藤类植物化石，人们在对其分散 的器官研究的基础上对其进行了复原 ${ }^{[8]}$. 最近人们从 南美洲早白严世地层中发现了两个与百岁兰科有关 的化石 ${ }^{[11,14]}$. 但是关于麻黄科, 研究表明许多与麻黄 粉相似的化石并不全都属于麻黄类 ${ }^{[3,17 \sim 21]}$, 同时尽管 有不少大化石被认为与麻黄有关, 但是却从未有过
整株化石的报道. 相当一部分化石要么只保存了植 物的一部分, 要么缺乏麻黄类特有的生殖器官来确 定其分类位置 ${ }^{[9,12,13,15,16,22,23]}$. 因此当分子证据显示不 同的结果时, 现代生物学家便很自然地怀疑起这些 化石证据的可靠性 ${ }^{[3,24226]}$. 尽管古植物学家在复原古 植物时倍加小心, 但是由于多少有人为因素的介人 难免出现一些偏差 ${ }^{[27,28]}$, 因此有多个器官有机相连 的整株保存的植物化石成为解决植物学中关于麻黄 起源时间争议吕需的重要证据. 本文中我们报道了 来自辽宁省西部早白严世义县组的两株完整保存、一 株部分保存的麻黄植物化石. 其中的整株麻黄化石 包括根、茎、枝、具株孔管的雌性单位. 这些化石的 出现确认了麻黄在早白严世的存在, 消除了关于麻 黄起源时间的争议. 这些化石的形态及其与鱼化石 的伴生把我们对于麻黄的生长习性、形态、生态和演 化的理解提高到了整株水平. 


\section{1 材料与方法}

本文研究的标本采集于辽宁省凌源市大王杖子 附近早白严世义县组 (1.25 亿年前) 地层的露头 $\left(41^{\circ} 15^{\prime} \mathrm{N}, 119^{\circ} 15^{\prime} \mathrm{E}\right)$. 此前在此发现过一种被子植物 一十字中华果 ${ }^{[29,30]}$. 虽然以前关于义县组的年 代问题争议颇多 ${ }^{[31 ~ 33]}$, 但是近期的工作似乎趋于 认同大约 1.22 1.25 亿年的年龄 ${ }^{[29,30,34,35]}$. 该化石 标本埋藏于灰色粉砂岩中(图 1). 化石的整体形貌用 Olympus 数字相机拍摄(图 1), 其中的形态细节用爱 国者观察王 GE-5 拍摄(图 2A F). 几个雌性单位的 细节通过先制模，再用 HF，HCI 清洗，然后镀金后
在中国科学院南京地质古生物研究所的 Leo1530 VP 扫描电子显微镜下进行观察(图 3A M). 所有照 片利用 Photoshop7.0 组合成图版, 并对放大倍数、 对比度和亮度进行了相应的调节, 对关键特征进行 了标注.

\section{2 结果}

目 尼藤目

科 麻黄科 属 麻黄属

种 洪涛麻黄(新种)Ephedra hongtaoi sp. nov.

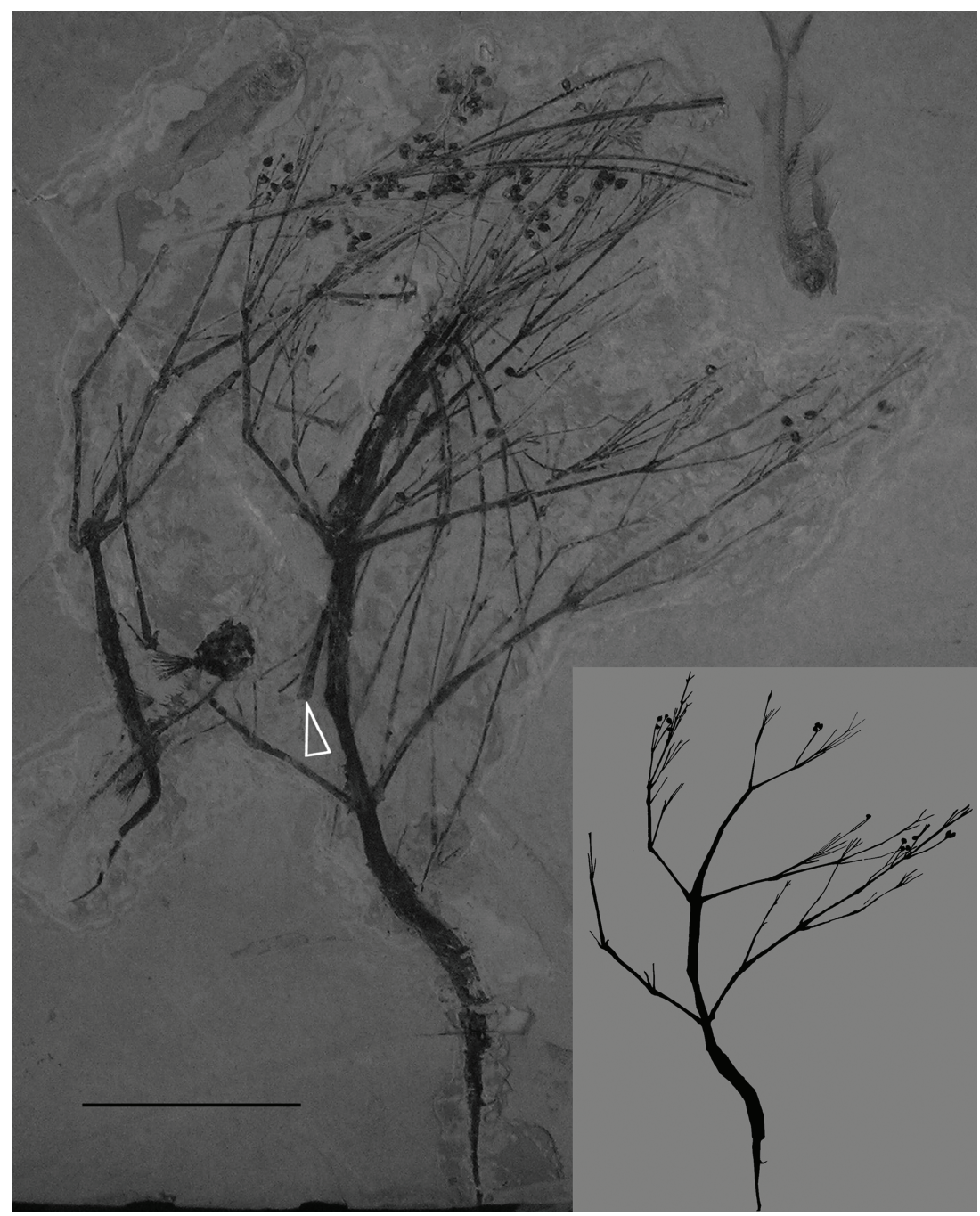

图 1 洪涛麻黄(新种)保存于同一块岩石上的 3 株植物

箭头所指的为一个部分保存的化石，另外两株为完整保存的植株; 注意其有机相连的根、茎、枝、交互对生的分支方式、顶生雌性单位、相 互缠绕的植株及伴生的茨康叶和中华狼鯺鱼; 右下插图中是一完整保存的植物的轮廍. 标尺长 $5 \mathrm{~cm}$ 

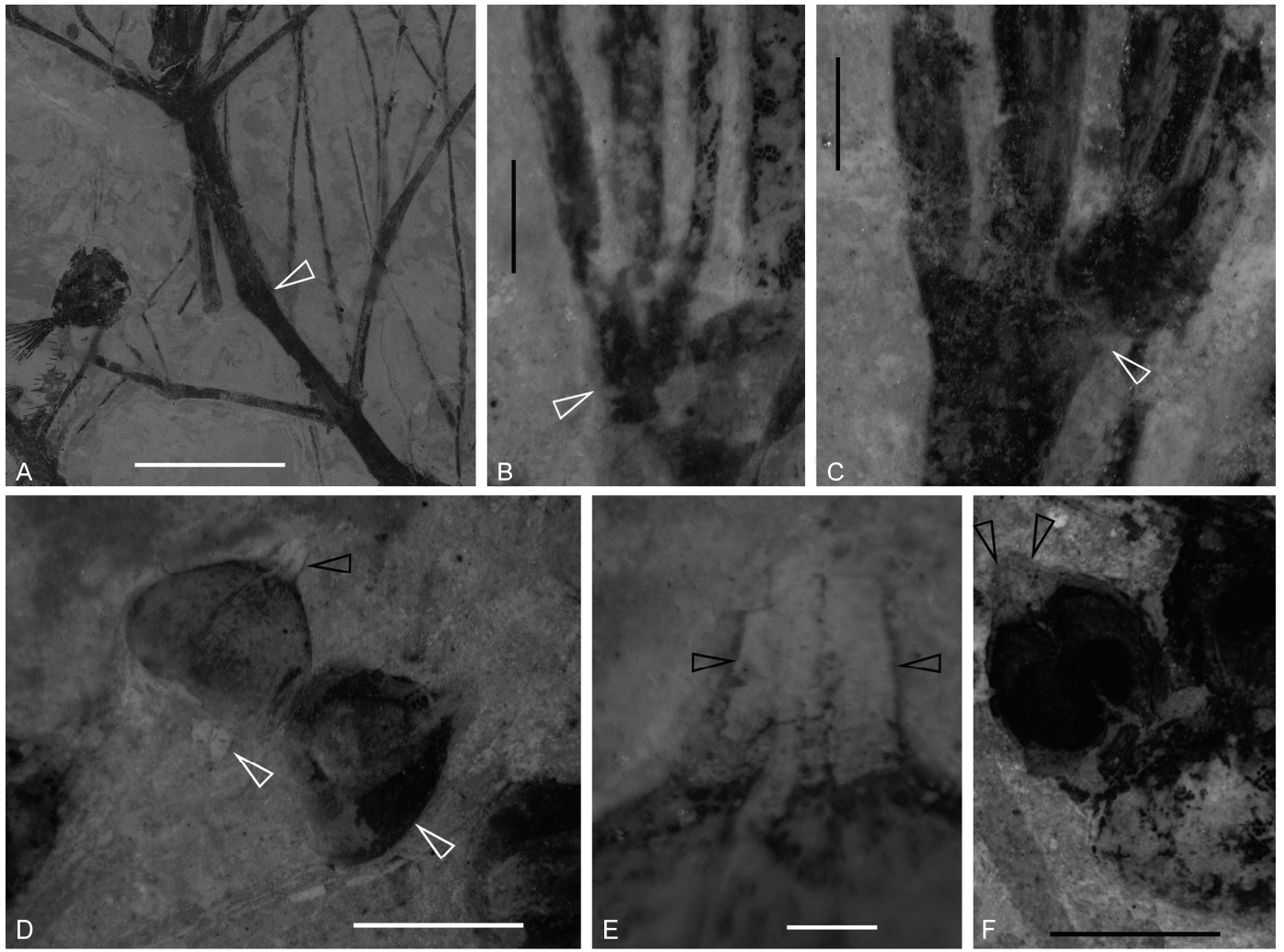

图 2 分枝及具珠孔管的顶生雌性单位的细节(实体镜照片)

$\mathrm{A}$, 交互对生的分支方式. 注意劲直的茎、枝、略膨大的节及左下角伴生的鱼. 箭头所指的节看起来似乎没有枝相连, 这是由于着生的枝垂直 于岩石层面. 标尺长 $2 \mathrm{~cm}$. B , 同一节(箭头)上的对生枝. 标尺长 $1 \mathrm{~mm}$. C, 同一节(箭头)上的对生枝及其上的纵纹. 标尺长 $1 \mathrm{~mm} . \mathrm{D}$, 枝上顶生 的雌性单位. 注意两个顶端的珠孔管(黑箭头, 放大于 $\mathrm{E}$ )、苍片的残迹(白箭头)、内外珠被的不同颜色. 标尺长 $2 \mathrm{~mm}$. $\mathrm{E}, \mathrm{D}$ 中两个珠孔管(箭头) 的细节. 注意内外珠被的不同颜色. 标尺长 $0.2 \mathrm{~mm}$. F, 枝上成对着生的雌性单位及其顶端上的珠孔管(箭头). 标尺长 $2 \mathrm{~mm}$

种征：植株高达 $26 \mathrm{~cm} ，$ 宽 $20 \mathrm{~cm}$ ，灌木，具根、 茎、枝及雌性单位，具明显的节和节间．主根宽 $7 \mathrm{~mm}$, 长 $8.5 \mathrm{~cm}$. 叶在化石中不可见. 茎劲直, 宽 $4.4 \mathrm{~mm}$, 节长达 $4.1 \mathrm{~cm}$. 枝细，交互对生，宽可达 $2.2 \mathrm{~mm}$ ，节 间可长达 $4.1 \mathrm{~cm}$, 雌性单位通常成对, 具顶生的珠孔 管，顶生于枝端.

词源: hongtaoi 赠与化石收集者蔡洪涛先生.

正型: GBM2, 保存于深圳市中国科学院仙湖植 物园古生物博物馆.

地点：辽宁省凌源市大王杖子 $\left(41^{\circ} 15^{\prime} \mathrm{N}, 119^{\circ}\right.$ $\left.15^{\prime} \mathrm{E}\right)$.

层位: 义县组(下白严统, 1.22 1.25 亿年前).

\section{1 描述}

该化石与中华狼鰙鱼和茨康叶共同埋藏于同一块 粉砂岩上(图 1). 共有 3 个植株位于同一岩板上(图 1).
虽然其中一棵植株残缺，但另外两棵植株却是完整 的，包括根、茎、枝和顶端具有珠孔管的雌性单位(图 1). 3 棵植物丛生在一起并且具有相同的朝向, 显示 出它们生活时的相互关系(图 1). 这些植物高 $18 \sim 26$ $\mathrm{cm}$, 宽 3.8 20 cm(图 1). 两棵植物具有强壮的主根, 粗 5 7 mm, 长 6.3 8.5 cm(图 1). 茎劲直, 交互对生, 具直的节间，在节处略有膨大，具纵纹(图 1, 2A C), 其节间粗 1.1 4.4 mm, 长 2.5 4.1 cm(图 1, 2A C ). 枝较细, 其节间粗 0.6 2.2 mm, 长 0.7 4.1 cm(图 1, 2A C). 叶不可见. 枝顶上有由 1 2 雌性单位组成的 不成型的球果(图 1,2D 和 F, 3A), 其苞片很少见，可 能交互对生(图 1,2D, 3I 和 J)。

雌性单位单个时近球状, $3.0 \mathrm{~mm} \times 2.3 \mathrm{~mm}$, 成对 时半球状, 宽 $2.2 \mathrm{~mm}$, 高 $1.8 \sim 2.7 \mathrm{~mm}$, 厚 1.1 1.3 $\mathrm{mm}$ (图 2D 和 F, 3A, D, I, K). 雌性单位由内外两层珠 被包裏(图 3D). 外珠被(变形的苍片)外表面粗粘, 内 

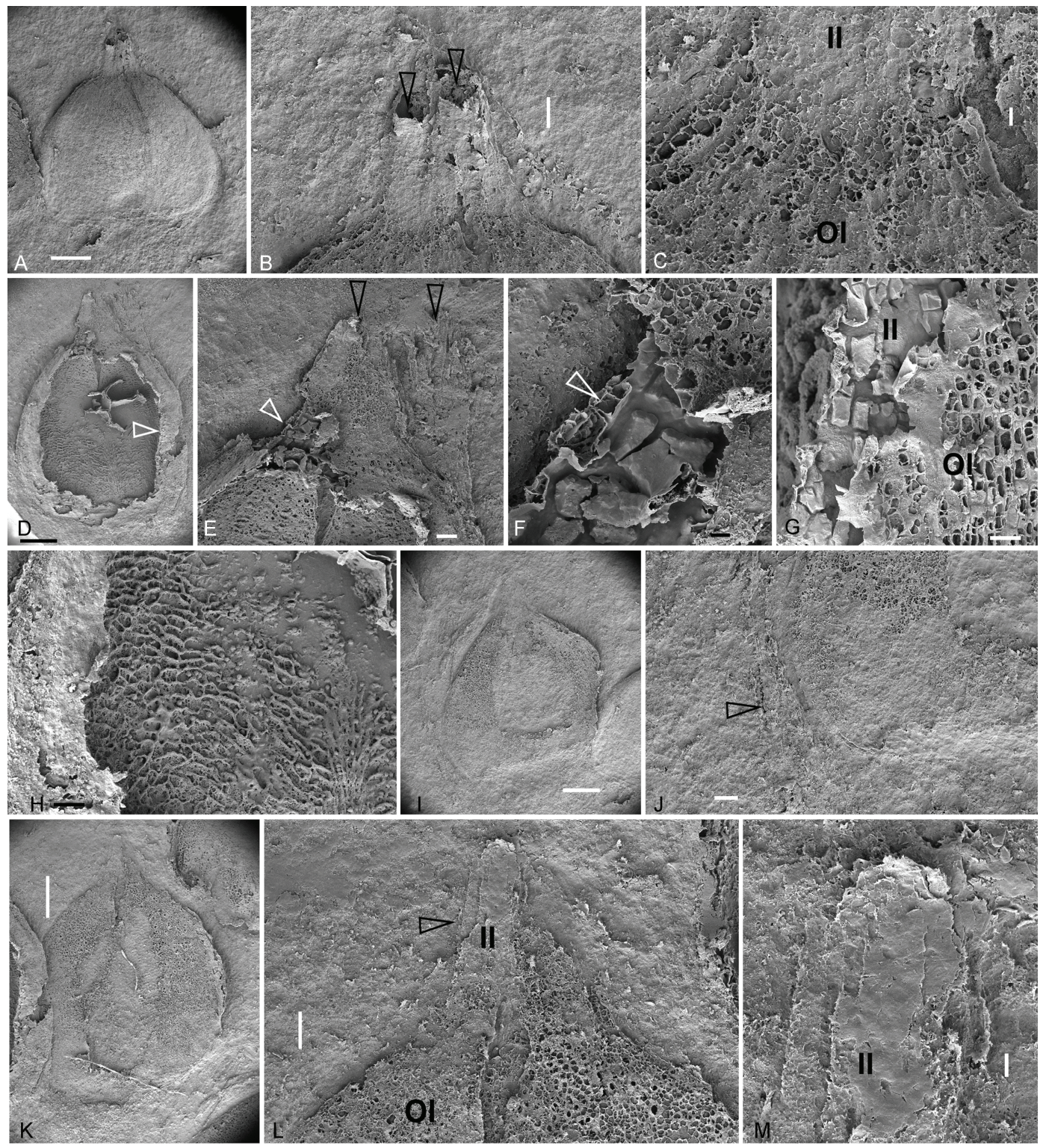

图 3 长有珠孔管的雌性单位的细节(扫描电子显微镜照片)

$\mathrm{A}$, 图 $2 \mathrm{D}$ 和 $2 \mathrm{E}$ 中雌性单位的细节. 注意雌性单位的形状及其顶端的珠孔管. 标尺长 $0.5 \mathrm{~mm}$. B, A 和图 $2 \mathrm{E}$ 中两个珠孔管的细节. 注意珠孔管 中的空腔(箭头). 标尺长 $0.1 \mathrm{~mm}$. C, 珠孔管(内珠被)与外珠被之间的过渡. 注意外珠被(OI)的表面粗粘, 珠孔管( II)表面光滑. 标尺长 $20 \mu \mathrm{m}$. D, 另一个雌性单位. 白箭头所指部分放大于 $\mathrm{G}$. 标尺长 $0.5 \mathrm{~mm}$. E, D 中的珠孔管(黑箭头), 白箭头所指部分放大于 $\mathrm{F}$. 标尺长 $0.1 \mathrm{~mm}$. $\mathrm{F}, \mathrm{E}$ 中白箭头 所指的部分中, 外珠被有光泽的内表面和解剖细节. 标尺长 $20 \mu \mathrm{m}$. G, D 中外珠被(OI)和内珠被( II)的细节. 注意内珠被有光泽的外表面. 标尺 长 $20 \mu \mathrm{m}$. H, D 中内珠被的细节. 标尺长 $0.1 \mathrm{~mm}$. I, 另一雌性单位及其下的苍片. 标尺长 $0.5 \mathrm{~mm}$. J, I 中雌性单位底部细节. 注意其下的苍片(箭 头). 标尺长 $0.1 \mathrm{~mm}$. $\mathrm{K}$, 另一对雌性单位. 标尺长 $0.5 \mathrm{~mm}$. L, $\mathrm{K}$ 中外珠被(OI)的粗䊁表面及珠孔管(箭头, II )的光滑表面. 标尺长 $0.1 \mathrm{~mm}$. M, L 中珠孔管( II)的光滑表面. 标尺长 $20 \mu \mathrm{m}$

表面有光泽(图 3F, G). 内珠被被外珠被覆盖时有光 泽(图 3G), 裸露时表面光滑并形成珠孔管(图 3B, L 和 M). 珠孔管粗 $0.15 \sim 0.29 \mathrm{~mm}$, 长 0.53 0.68 mm, 内具 有一个管道，向顶稍尖，着生于雌性单位顶部(图 2D F, 3B, E, L). 显然这些植株尚未成熟结籽, 故种

\section{子未知.}

\section{2 说明}

交互对生的分支方式和带有珠孔管的雌性单位 一起把这些植物的分类位置限制到了尼藤目中. 尽 
管麻黄、百岁兰和尼藤三者有很多共有特征，但是三 者之间的区别也是明显的. 它们的叶子十分不同: 尼 藤的叶子类似双子叶植物的, 百岁兰的叶子呈带状, 麻黄的叶子十分退化, 不明显. 它们的生长方式也迥 然不同：尼藤为交互对生分支的藤本或木本，百岁兰 的地下茎粗壮、没有分支, 麻黄的茎纤细、交互对生 分支. 麻黄的雌性生殖器官与尼藤和百岁兰的不同, 后两者具有十分明确的、苍片轮生或交互对生的、很 成形的球果 ${ }^{[6]}$. 鉴于这些区别, 我们的化石很显然与 麻黄科关系更加密切.

我们之所以把这些化石置于麻黄属而不建立一 个新属的原因在于, 这些化石和现生的麻黄在生长 习性、交互对生分支方式、主根、退化的叶、顶生不 成形球果、珠孔管、节和节间等方面没有任何区别. 况且此前已有把白严纪的大化石和离散的种子置于 麻黄属的先例 ${ }^{[15,16]}$. 除了古斑子麻黄和斑子麻黄之 间生殖器官上共享的特征外 ${ }^{[15]}$, 我们的化石 (洪涛麻 黄)还与现生的麻黄具有相同的生长习性. 这一切使 我们相信, 洪涛麻黄代表着麻黄属中古老的一员,

\section{3 讨论与结论}

\section{1 与化石麻黄种类的比较}

此前与麻黄有关系的化石已有报道 ${ }^{[9,12,15,36]}$. 中 国似麻黄和明显似麻黄产自青海下侏罗统 ${ }^{[9]}$. 此两种 与我们描述的新种的共同之处在于交互对生的分支 方式、明显的节和节间、可能的雌性球果，但是关于 此两种的雌性球果和肧珠/种子的详情不知, 无法进 一步比较. 产自吉林下白严统的星学异麻黄是化石 记录中唯一一个没有交互对生分支的麻黄, 也由此 与我们的化石区分开来，该化石仅保存植物的顶端 部分, 但是其带有珠孔管的、顶生的雌性单位却与现 生麻黄十分相似 ${ }^{[12]}$. 产自辽西下白严统的古斑子麻 黄与我们的新种在诸多方面十分相似，包括顶生的 雌生球果、交互对生的分支方式、带纵纹的枝、珠孔 管以及相同的时代与地域. 但是二者处于不同的发 育阶段和保存状态使得进一步的比较不太可能：洪 涛麻黄没有成熟的种子可以与古斑子麻黄比较, 而 后者仅保存了植物的顶端部分 ${ }^{[15]}$. 产自辽西下白严 统的陈氏辽西草及该属的其他种具有交互对生的分 支方式、明显的节及节间、枝表面具纵纹 ${ }^{[36]}$, 这些特 征都和我们的新种相似. 但是辽西草的特征并不仅 限于麻黄, 而且文献[36]中所展示的辽西草的雌性球
果并没有其作者所声称的麻黄类典型的交互对生的 苍片排列方式. 而在我们和其他麻黄化石 ${ }^{[12,15]}$ 中常 见的、尼藤类典型的珠孔管在辽西草中也没有发现 考虑到辽西草所展示的分支方式在东北繁缕(石竹 科)、无叶假木贼(藜科)及其他被子植物中亦有出现, 因此此特征同时可以把辽西草与麻黄和被子植物联 系起来. 故此辽西草在没有明显的尼藤类生殖器官 特征的情况下不能令人信服地将其归人到尼藤类中 去. Drewria potomacensis ${ }^{[8]}$ 是一种产自北美东部下白 严统的化石植物, 其很可能是一种灌木, 具交互对生 分支方式、明显的节和节间，节间略有膨大，叶具平 行叶脉和 V 字形间脉, 苍片交互对生, 可能具有珠孔 管. Crane 和 Upchurch ${ }^{[8]}$ 通过研究该植物分散的营养和 生殖器官对该植物进行了复原. 这也许是此前研究 最细的尼藤类化石了, 但是其发育良好的叶使之与 麻黄格格不人, 这一点在其他麻黄化石和现生种类 完全一致地表现出退化的叶的情况下尤为突出(表 1).

\section{2 与现生麻黄的比较}

洪涛麻黄与现生种类在诸多方面十分相似，例 如灌木生长习性、主根、分支方式、茎、枝上的纵纹、 明显的节与节间、细的枝、退化的叶、带珠孔管的雌 性单位. 它比某些中国的麻黄种类(如 $26 \mathrm{~cm}$ 高的膜 果麻黄等)个体小, 比另外一些(如单子麻黄等)大, 与 草麻黄(及另外几种)大体相当 ${ }^{[37]}$ (表 1). 值得一提的 是, 草麻黄今天就生长在中国辽宁 ${ }^{[37]}$, 正是产出本 化石的区域. 除上述的相同之处外，草麻黄和洪涛麻 黄还共有顶生的雌性球果(表 1). 想象一下, 经历了这 么长时间的地质历史的变化, 这两者相关的种类还 共享着这么相似的特征和生活空间，本身就是一件 很有意思的事情. 这和活化石舌形贝的情形有些相 似，只是后者的时间跨度更大而已.

\section{3 辨别麻黄化石}

虽然尼藤类的微体化石在白严纪十分丰富，而 且与它们有关的大化石记录也在不断增加, 但是由 于种种原因真正属于尼藤类的大化石还是十分稀少 的. 原因之一在于鉴定这些化石十分困难. 尼藤类大 化石与双子叶和松柏类的很难区分，因而很容易被 当作后者来记述 ${ }^{[10]}$. 原因之二在于其草本或灌木生 长习性减少了它们形成化石的可能性 ${ }^{[10]}$. 但是中生 代尼藤类的灌木习性，除了 Crane 和 $\mathrm{Upchurch}^{[8]}$ 的 
表 1 洪涛麻黄、现生麻黄和其他可能与麻黄有关的大化石的对比

\begin{tabular}{|c|c|c|c|c|c|c|c|c|c|}
\hline & $\begin{array}{c}\text { 洪涛麻黄 } \\
\text { (新种) }\end{array}$ & 斑子麻黄 ${ }^{[37]}$ & $\begin{array}{l}\text { 草麻 } \\
\text { 黄 }^{[37]}\end{array}$ & $\begin{array}{l}\text { 古斑子 } \\
\text { 麻黄 }\end{array}$ & $\begin{array}{l}\text { 星学异 } \\
\text { 麻黄 }\end{array}$ & $\begin{array}{l}\text { 中国似 } \\
\text { 麻黄[9] }\end{array}$ & $\begin{array}{c}\text { 明显似麻 } \\
\text { 黄 }\end{array}$ & $\begin{array}{l}\text { 陈氏辽 } \\
\text { 西草 }{ }^{[36]}\end{array}$ & $\begin{array}{l}\text { Drewria poto- } \\
\text { macensis }^{[8]}\end{array}$ \\
\hline 株高 & $26 \mathrm{~cm}$ & $15 \sim 30 \mathrm{~cm}$ & 可达 $40 \mathrm{~cm}$ & - & - & - & - & - & - \\
\hline 根 & 主根 & 主根 & 主根 & - & - & - & - & - & - \\
\hline 生长习性 & 灌木 & 灌木 & 灌木 & 灌木? & 灌木? & 灌木? & 灌木? & 灌木? & 草本 \\
\hline 茎/枝 & $\begin{array}{c}\text { 交互对生, } \\
0.6 \sim 4.2 \mathrm{~mm} \text { 宽 }\end{array}$ & $\begin{array}{c}\text { 交互对生, } \\
1 \mathrm{~mm} \text { 宽 }\end{array}$ & $\begin{array}{l}\text { 交互对生, } \\
2 \mathrm{~mm} \text { 宽 }\end{array}$ & $\begin{array}{c}\text { 交互对生, } \\
1 \mathrm{~mm} \text { 宽 }\end{array}$ & $\begin{array}{c}\text { 二叉分支, } \\
1 \text { mm 宽 }\end{array}$ & $\begin{array}{c}\text { 交互对生, } \\
1 \mathrm{~mm} \text { 宽 }\end{array}$ & $\begin{array}{l}\text { 交互对生, } \\
2 \sim 5 \mathrm{~mm} \text { 宽 }\end{array}$ & $\begin{array}{l}\text { 交互对生, } \\
3 \mathrm{~mm} \text { 宽 }\end{array}$ & $\begin{array}{l}\text { 交互对生, } \\
3 \mathrm{~mm} \text { 宽 }\end{array}$ \\
\hline $\begin{array}{c}\text { 节间长 } \\
\text { 节 }\end{array}$ & $\begin{array}{l}\text { 7 41 mm } \\
\text { 略有膨大 }\end{array}$ & $\begin{array}{l}10 \sim 15 \mathrm{~mm} \\
\text { 略有膨大 }\end{array}$ & $\begin{array}{l}25 \sim 55 \mathrm{~mm} \\
\text { 略有膨大 } \\
\text { 或不膨大 }\end{array}$ & $\begin{array}{l}8 \sim 14 \mathrm{~mm} \\
\text { 不膨大 }\end{array}$ & $\begin{array}{l}4 \sim 9 \mathrm{~mm} \\
\text { 不膨大 }\end{array}$ & $\begin{array}{l}6 \sim 10 \mathrm{~mm} \\
\text { 略有膨大 }\end{array}$ & $\begin{array}{l}8 \sim 15 \mathrm{~mm} \\
\text { 略有膨大 }\end{array}$ & $\begin{array}{l}8 \sim 40 \mathrm{~mm} \\
\text { 略有膨大 }\end{array}$ & $\begin{array}{c}\text { 可达 } 30 \mathrm{~mm} \\
\text { 略有膨大 }\end{array}$ \\
\hline $\begin{array}{l}\text { 茎表面 } \\
\text { 叶 }\end{array}$ & $\begin{array}{l}\text { 具纵纹 } \\
\text { 高度退化 }\end{array}$ & $\begin{array}{l}\text { 具纵纹 } \\
\text { 每节 } 2 \text { 枚, } \\
1 \mathrm{~mm} \text { 长, } \\
\text { 三角形 }\end{array}$ & $\begin{array}{c}\text { 具纵纹 } \\
\text { 每节 } 2 \text { 枚, } \\
5 \mathrm{~mm} \text { 长, } \\
\text { 三角形 }\end{array}$ & $\begin{array}{c}\text { 具纵纹 } \\
\text { 每节 } 2 \text { 枚, } \\
5 \mathrm{~mm} \text { 长, } \\
\text { 三角形 }\end{array}$ & $\begin{array}{c}\text { 具纵纹 } \\
\text { 每节 } 1 \text { 枚, } \\
\text { 退化, } \\
\text { 三角形 }\end{array}$ & $\begin{array}{l}\text { 具纵纹 } \\
\text { 每节 2 3 } \\
\text { 枚, 退化 }\end{array}$ & 具纵纹 & $\begin{array}{c}\text { 具纵纹 } \\
\text { 每节 } 2 \text { 枚, } \\
\text { 线形, } \\
7 \mathrm{~mm} \text { 长 }\end{array}$ & $\begin{array}{c}\text { 具纵纹 } \\
\text { 每节 } 2 \text { 枚, 长 } \\
\text { 圆形, 10 20 } \\
\mathrm{mm} \text { 长 }\end{array}$ \\
\hline $\begin{array}{c}\text { 雌性球果 } \\
\text { 苍片 }\end{array}$ & $\begin{array}{c}\text { 顶生 } \\
2 \text { 对(?), } \\
\text { 交互对生(?) }\end{array}$ & $\begin{array}{c}\text { 顶生 } \\
2 \sim 3 \text { 对, } \\
\text { 交互对生 }\end{array}$ & $\begin{array}{c}\text { 顶生/腋生 } \\
4 \text { 对, } \\
\text { 交互对生 }\end{array}$ & $\begin{array}{c}\text { 顶生 } \\
2 \text { 对, } \\
\text { 交互对生 }\end{array}$ & $\begin{array}{c}\text { 顶生 } \\
2 \sim 8 \text { 对, } \\
\text { 交互对生 }\end{array}$ & 顶生 & - & $\begin{array}{c}\text { 顶生/腋生 } \\
2 \sim 6 \text { 对, } \\
\text { 交互对生? }\end{array}$ & $\begin{array}{l}\text { 顶生/腋生 } \\
\text { 可达 } 6 \text { 对, } \\
\text { 交互对生 }\end{array}$ \\
\hline 肧珠/种子 & $\begin{array}{c}\text { 半球形, 成 } \\
\text { 对或单独, } \\
2.7 \mathrm{~mm} \times 2.2 \mathrm{~mm}\end{array}$ & $\begin{array}{c}\text { 卵圆形, 成 } \\
\text { 对, } 8 \mathrm{~mm} \times \\
3 \mathrm{~mm}\end{array}$ & $\begin{array}{c}\text { 长卵圆形,成 } \\
\text { 对, } 6 \mathrm{~mm} \\
\times 3 \mathrm{~mm}\end{array}$ & $\begin{array}{c}\text { 长卵圆形, } \\
\text { 成对或单独, } \\
7.5 \mathrm{~mm} \times 2.2 \mathrm{~mm}\end{array}$ & $\begin{array}{l}\text { 椭圆形, 成 } \\
\text { 对, } 4.5 \mathrm{~mm} \\
\times 1.5 \mathrm{~mm}\end{array}$ & $\begin{array}{l}\text { 椭圆形, 成 } \\
\text { 对, } 2 \mathrm{~mm} \\
\times 1 \mathrm{~mm}\end{array}$ & $\begin{array}{c}\text { 椭圆形, } \\
\text { 成对 }\end{array}$ & $\begin{array}{l}\text { 卵圆形, 单 } \\
\text { 个, } 1.1 \mathrm{~mm} \\
\times 0.7 \mathrm{~mm}\end{array}$ & $\begin{array}{c}\text { 扁平, 卵圆形, } \\
2.5 \mathrm{~mm} \\
\times 2 \mathrm{~mm}\end{array}$ \\
\hline $\begin{array}{c}\text { 珠孔管 } \\
\text { 生境 }\end{array}$ & $\begin{array}{l}+, 0.56 \mathrm{~mm} \text { 长 } \\
\text { 温热, 不干燥 }\end{array}$ & $\begin{array}{l}+, 1 \sim 2 \mathrm{~mm} \text { 长 } \\
\text { 温热, 干燥 }\end{array}$ & $\begin{array}{c}+, 1 \sim 2 \mathrm{~mm} \text { 长 } \\
\text { 温热, 干燥 }\end{array}$ & $\begin{array}{l}+, 1 \sim 2 \mathrm{~mm} \text { 长 } \\
\text { 中度, 不干燥 }\end{array}$ & $\begin{array}{l}+, 1 \mathrm{~mm} \text { 长 } \\
\text { 温热, 不干燥 }\end{array}$ & $\bar{?}$ & - & 温热, 干燥 & $\begin{array}{c}+? \\
\text { 温热, 不干燥 }\end{array}$ \\
\hline $\begin{array}{c}\text { 保存状态 } \\
\text { 地点 }\end{array}$ & $\begin{array}{l}\text { 整株 } \\
\text { 辽宁 }\end{array}$ & $\begin{array}{l}\text { 整株 } \\
\text { 华北 }\end{array}$ & $\begin{array}{l}\text { 整株 } \\
\text { 辽宁 }\end{array}$ & $\begin{array}{c}\text { 部分保存 } \\
\text { 辽宁 }\end{array}$ & $\begin{array}{c}\text { 部分保存 } \\
\text { 吉林 }\end{array}$ & $\begin{array}{c}\text { 部分保存 } \\
\text { 青海 }\end{array}$ & $\begin{array}{c}\text { 部分保存 } \\
\text { 青海 }\end{array}$ & $\begin{array}{c}\text { 部分保存 } \\
\text { 辽宁 }\end{array}$ & $\begin{array}{c}\text { 复原 } \\
\text { 美国佛吉 } \\
\text { 尼亚 }\end{array}$ \\
\hline 年代 & 巴雷姆期 & 现代 & 现代 & 巴雷姆期 & $\begin{array}{l}\text { 阿普特- } \\
\text { 阿尔布期 }\end{array}$ & 早侏罗世 & 早侏罗世 & $\begin{array}{c}\text { 阿普特-阿 } \\
\text { 尔布期 }\end{array}$ & 阿普特期 \\
\hline
\end{tabular}

文章外, 时至今日没有太多的化石证据支持. 除了

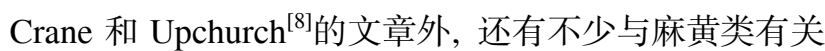
的化石报道 ${ }^{[9,12,15,22,23,36]}$, 其中的大多数只是关于部 分植物的报道. 这些证据不足以说服那些从另一个 背景和角度来研究麻黄的分子系统学家 ${ }^{[3]}$. 他们认为, DNA 序列比在他们看来过于破碎的化石更加可靠.

尽管关于麻黄的化石报道不在少数, 但我们不 得不保持清醒, 从中篮选可靠的证据. 类似麻黄花粉 的报道, 如 Ephedripites, Gnetaceaepollenites, Equisetosporites, Cornetipollis 及似麻黄粉, 已经被不同的 学者在各种地层和形态迥异的器官(如 Masculostrobus, Piroconites, Eoantha, Palaeognetaleana 及 Eucommiitheca) 中发现 ${ }^{[1721]}$. 其中很多雄性球果和尼藤类 的区别很大. 因而不太可能与尼藤类有密切的关 系 ${ }^{[17 \sim 9]}$, 因此不能把它们作为麻黄或百岁兰在某一 地区或时段的代表 ${ }^{[3]}$. Crane $\mathrm{e}^{[10]}$ 在评价尼藤类化石记 录时十分谨慎. 他列举了尼藤类的 6 或 8 个共有衍征, 而且提醒人们, 除了其中一个外, 所有这些特征都不 是尼藤类特有的. Crane $\mathrm{e}^{[10]}$ 呼吁人们去注意那些具有
交互对生的分支方式和非典型的松柏类球果的化石 很不幸的是, 有些古植物学家看起来是把这个呼吁 当成了鉴定尼藤类化石的标准. 例如, 很多放人尼藤 类的化石只具有这种交互对生的分支方式而没有生 殖器官和其他的相关特征 ${ }^{[22,23,31,32,36]}$. 实际上这种分 支方式本身并没有人们想象的那么大的分类学意义. 因此要把这些化石确切地放人到麻黄属至少需要更 加令人信服的证据, 因为某些被子植物如东北繁缕 (石竹科)和无叶假木贼(嵊科)有着与这些化石难以区 别的分支方式. 因为非古植物学家不可能会注意这 些化石细节, 维护化石记录的可靠性对于古植物学 家来说是责无旁贷的, 因此我们建议只保留那些完 整保存的或者部分保存的但具有清晰的麻黄生殖器 官特征的化石, 而把其他的化石归人到可能与麻黄 有关系的类群中去.

\section{4 生态、演化与起源时间}

过去在古植物学中有很多古植物是在研究分散 的植物器官后通过拼合重建起来的. 这些重建的优 
点在于能够直观地向公众展示植物化石的全貌. 虽 然其中不乏成功的案例, 但是这种工作并不完全可 靠, 需要人们警惕其中的人为因素. 例如最近发现的 在 Erdtmanispermum ${ }^{[38]}$ 重建过程中的错误再次为我 们敲响了警钟 ${ }^{[28,39]}$ : 虽然是出于良好的意愿, 但是这 种重建过程相当复杂, 需要人们关注其中的每一个 细节, 很容易出现错误, 而这些细节上的错误即使是 评审人, 更别说普通公众, 也未必能够识别出来. 这 种错误一旦进人文献记录就非常难以清除其影响. 更为糟糕的是, 这会为类似的工作带来挥之不去的 怀疑：“这里边还有没有未发现的错误?”. 因此有机 相连的不同器官, 尤其是整体保存的植物化石, 就显 得无比重要了, 它们的价值远远大于几个器官之和. 虽然过去关于麻黄化石的报道不少，但是这些支离 破碎的材料对于进一步进行相互对比和研讨麻黄的 生态帮助不大. 而关于麻黄的有些信息, 如生长习 性、总体面貌、演化和生态，在没有几个整株保存的 化石的情况下是无法准确复原的. 而本文报道的化 石为我们获取这些关于麻黄的亟需的信息提供了一 个难得的机会.

自从早白严世以来, 麻黄的形态演化似乎一直 处于停滞状态 ${ }^{[13,15,40]}$. 除了星学异麻黄 ${ }^{[2]}$ 外, 其他所 有与麻黄有关的大化石, 包括我们的新种, 都一致表 现出相似的交互对生分支方式、顶生雌性球果、茎枝 上带有纵纹、具明显的节和节间和高度退化的叶 ${ }^{[9,15]}$. 除了上述相似特征外, 洪涛麻黄和现生的麻黄在灌 木习性、主根和珠孔管等方面也没有什么区别. 虽然 我们还不能证明, 我们也并不相信我们的新种和麻 黄现生的冠群直接相关, 但是它们充分证明了麻黄 形态演化中长期的停滞. 与现生麻黄 ${ }^{[3]}$ 类似, 卷柏水非及合囊藓-观音莲座硕的现生种类在分子钟上也 表现出了人们难以解释的低演化速率 ${ }^{[16]}$. 这个低演 化速率和麻黄形态演化上的停滞可能部分解释为什 么分子钟研究中麻黄显得过于年轻 ${ }^{[3,24226]}$. 基于对部 分保存的植物大化石的不信任、麻黄生境的近期出 现、来源于不同植物的类似麻黄花粉, Huang 和 Price ${ }^{[3]}$ 认为麻黄只是起源于近代. 他们认为只有保存完好 的麻黄大化石才有资格对他们的结论作出评价. 我 们希望我们这里报道的整株保存的麻黄化石能够满 足他们的严格要求, 有助于消除他们对于化石材料 的顾虑. 另外一种解释是, Huang 和 Price ${ }^{[3]}$ 所推断的 只是麻黄冠群，而非整个麻黄属的起源时间. 目前状
况下，我们尚无从判断到底是缓慢的分子演化速率， 还是取样于冠群，或是二者的组合，导致了他们的 研究结果, 但是有一点是明确的, 即麻黄(至少是其 干群)在早白普世就已经出现. 假若这些白严纪的麻 黄化石属于已灭绝的、现生类群的姊妹类群, 并且最 近发生的麻黄再次分化在形态学上没有留下任何痕 迹的话，那么这些只保留了形态学信息的大化石对 于回答关于麻黄冠群起源时间的问题就变得无能为 力了 ${ }^{[13]}$.

植物化石的保存是与搬运的距离和水流的速度 相关联的. 要想完好保存植物, 要么只搬运了很短距 离, 要么水流的速度很慢, 或者二者兼而有之. 否则, 植物就会解体或至少排列方向上有所变化. 洪涛麻 黄的个体较大, 排除了水流较缓的可能性, 因为过缓 的水流不大可能将其搬运到沉积埋藏地点. 3 株埋藏 在一起，植物大小相似，相互间关系和谐，这表明三 者很可能保留着其生活时的相互关系，它们也许在 生活时共同组成了当时当地植被的一部分一一小 丛灌木. 它们之间空间关系的和谐性暗示它们的生 境距离沉积埋藏地点并不太远. 此前已经有不少关 于义县组, 尤其是四合屯地区, 古环境的研究工作 结果表明, 这里的湖相静水环境常常受到季节性洪 水和火山灰的影响, 使得很多化石得以精美地保存 下来 ${ }^{[41 ~ 44]}$. 虽然凌源大王丈子的古环境并不一定与 四合屯地区完全相同，但是前人曾经把其解释为湖 相 ${ }^{[29,30]}$. 我们在同一块化石上观察到的中华狼鳍鱼 (热河生物群中典型的淡水鱼种)支持这种解释(图 1). 实际上该块化石上共计有 7 条狼鲜鱼，它们的存在十 分强烈地指向淡水湖泊环境, 也同时支持了洪涛麻 黄生境并不远离水体的结论. 其与洪涛麻黄的伴生 支持了前人麻黄并不总是生活于干旱环境，而其现 生种类对于干旱环境的适应是自早白严世以来长期 适应的结果的结论 ${ }^{[2]}$. Huang 和 Price ${ }^{[3]}$ 提出麻黄近代 起源说的部分原因即是其所生活的环境只是在近代 才出现的. 他们认为, 化石和现生的麻黄都统统生活 于干旱的环境中. 但是先前 ${ }^{[12]}$ 和我们的化石证据表 明他们的这个默认前提在早白严世并不成立，因此 进一步削弱了他们的论据.

现生麻黄中的雌性球果有不同的着生方式 ${ }^{[37]}$. 顶生球果在早期麻黄中的出现暗示顶生的球果并不 像以前人们所认为的那样进化 ${ }^{[9,12,15]}$. 我们的化石进 一步支持了这一结论. 我们希望这有助于未来分支 
分类学中有关性状极性和编码的确定.

洪涛麻黄确认了义县组麻黄的灌木生长习性. Yang 等人 ${ }^{[15]}$ 在研究部分保存的麻黄化石时无法确定 其生长习性，他们寄希望于未来更好的化石来回答 这个问题. 在前人的基础上 ${ }^{[9,12,15]}$, 我们的化石证据 充分证明了麻黄的灌木生长习性. Crane ${ }^{[10]}$ 说过, 灌
木习性减少了麻黄形成化石的可能性, 这部分解释 了麻黄化石的稀缺性.

洪涛化石和早白严世发现的百岁兰类化石 ${ }^{[11,14]}$ 迥然不同，表明这两个谱系早在早白严世即已完全 成形，而其共同祖先必然出现在白严纪以前的地层 中, 正如 Rydin 等人 ${ }^{[11]}$ 所言.

\section{参考文献}

1 Crane P R. Phylogenetic analysis of seed plants and the origin of angiosperms. Ann Miss Bot Gard, 1985, 72: 716-793

2 Doyle J A, Donoghue M J. Seed plant phylogeny and the origin of angiosperms: An experimental cladistic approach. Bot Rev, 1986, 52: $321-431$

3 Huang J, Price R A. Estimation of the age of extant Ephedra using chloroplast $r b c \mathrm{~L}$ sequence data. Mol Biol Evol, 2003, 20: 435-440

4 Qiu Y L, Li L B, Wang B, et al. A nonflowering land plant phylogeny inferred from nucleotide sequences of seven chloroplast, mitochondrial, and nuclear genes. Intl J Plant Sci, 2007, 168: 691-708

5 Doyle J A. Integrating molecular phylogenetic and paleobotanical evidence on origin of the flower. Intl J Plant Sci, 2008, 169: 816-843

6 Chamberlain C J. Gymnosperms, Structure and Evolution. New York: Johnson Reprint Corporation, 1957. 1—484

7 Bierhorst D W. Morphology of Vascular Plants. New York: Macmillan Company, 1971. 1—560

8 Crane P R, Upchurch G R J. Drewria potomacensis gen. et sp. nov., an Early Cretaceous member of Gnetales from the Potomac Group of Virginia. Amer J Bot, 1987, 74: 1722-1736

9 吴向午, 何元良, 梅盛吴. 似麻黄属 Ephedrites 在青海下侏罗统小煤沟组的发现. 古植物学与孢粉学文集, 1986, 1: 13-21

10 Crane P R. The fossil history of Gnetales. Intl J Plant Sci, 1996, 157: S50—S57

11 Rydin C, Mohr B, Friis E M. Cratonia cotyledon gen. et sp. nov.: A unique Cretaceous seedling related to Welwitschia. Proc Roy Soc B, 2003, 270: S29-S32

12 陶君容, 杨永. 吉林延边早白严世大拉子组植物化石新类型一一星学异麻黄. 古生物学报, 2003, 42: 208一215

13 Rydin C, Pedersen K J, Friis E M. On the evolutionary history of Ephedra: Cretaceous fossils and extant molecules. Proc Natl Acad Sci USA, 2004, 101: 16571-16576

14 Dilcher D L, Bernardes-de-Oliveira M E, Pons D, et al. Welwitschiaceae from the Lower Cretaceous of northeastern Brazil. Amer J Bot, 2005, 92: 1294-1310

15 Yang Y, Geng B Y, Dilcher D L, et al. Morphology and affinities of an Early Cretaceous Ephedra (Ephedraceae) from China. Amer J Bot, 2005, 92: 231-241

16 Rydin C, Pedersen K R, Crane P R, et al. Former diversity of Ephedra (Gnetales): Evidence from Early Cretaceous seeds from Portugal and North America. Ann Bot, 2006, 98: 123-140

17 Ash S R. Late Triassic plants from the Chinle Formation in north-eastern Arizona. Palaeontology, 1972, 15: 598_618

18 Krassilov V A. New floral structure from the Lower Cretaceous of Lake Baikal area. Rev Palaeobot Palyn, 1986, 47: 9—16

19 Van Konijnenburg-Van Cittert J H A. An enigmatic Liassic microsporophyll, yielding Ephedripites pollen. Rev Palaeobot Palyn, 1992, 71 : $239-254$

20 Friis E M, Pedersen K R. Eucommiitheca hirsuta, a new pollen organ with Eucommiidites pollen from the Early Cretaceous of Portugal. Grana, 1996, 35: 104-112

21 Wang Z Q. A new Permian gnetalean cone as fossil evidence for supporting current molecular phylogeny. Ann Bot, 2004, 95: 281-288

22 吴舜卿. 辽西热河植物群初步研究. Palaeoworld, 1999, 11: 7-57

23 郭双兴, 吴向午. 辽宁西部晚株罗世晚期义县组的似麻黄属植物. 古生物学报, 2000, 39: 81-91

24 Huang J, Giannasi D E, Price R A. Phylogenetic relationships in Ephedra (Ephedraceae) inferred from chloroplast and nuclear DNA sequences. Mol Phyl Evol, 2005, 35: 48-59

25 王庆彪，王莉，周仁超，等. 用叶绿体和核糖体 DNA 序列探讨中国特有植物斑子麻黄的系统位置. 科学通报, 2006, 51: 110一113

26 Won H, Renner S S. Dating dispersal and radiation in the gymnosperm Gnetum (Gnetales)—Clock calibration when outgroup relation- 
ships are uncertain. Syst Biol, 2006, 55: 610-622

27 Kvacek Z. Whole-plant reconstructions in fossil angiosperm research. Intl J Plant Sci, 2008, 169: 918-927

28 Rothwell G W, Crepet W L, Stockey R A. Is the anthophyte hypothesis alive and well? New evidence from the reproductive structures of Bennettitales. Amer J Bot, 2009, 96: 296-322

29 Leng Q, Friis E M. Sinocarpus decussatus gen. et sp. nov., a new angiosperm with basally syncarpous fruits from the Yixian Formation of Northeast China. Plant Syst Evol, 2003, 241: 77-88

30 Leng Q, Friis E M. Angiosperm leaves associated with Sinocarpus Leng et Friis infructescences from the Yixian Formation (mid-Early Cretaceous) of NE China. Plant Syst Evol, 2006, 262: 173-187

31 Sun G, Dilcher D L, Zheng S L, et al. In search of the first flower: A Jurassic angiosperm, Archaefructus, from Northeast China. Science, 1998, 282: 1692-1695

32 Sun G, Zheng S, Dilcher D, et al. Early Angiosperms and Their Associated Plants from Western Liaoning, China. Shanghai: Shanghai Technology \& Education Press, 2001. 1-227

33 Swisher C C, Wang Y Q, Wang X L, et al. Cretaceous age for the feathered dinosaurs of Liaoning. Nature, 1999, 400: 58-61

34 Li J, Batten D J. Palynological evidence of an Early Cretaceous age for the Yixian Formation at Sihetun, western Liaoning, China. Cret Res, 2007, 28: 333-338

35 Dilcher D L, Sun G, Ji Q, et al. An early infructescence Hyrcantha decussata (comb. nov.) from the Yixian Formation in northeastern China. Proc Natl Acad Sci USA, 2007, 104: 9370_-9374

36 Rydin C, Wu S, Friis E. Liaoxia Cao et S.Q. Wu (Gnetales): Ephedroids from the Early Cretaceous Yixian Formation in Liaoning, northeastern China. Plant Syst Evol, 2006, 262: 239-265

37 Fu L K, Yu Y, Riedl H. Ephedraceae. In: Wu Z Y, Raven P H, eds. Flora of China. Beijing: Science Press, 1999. 97-101

38 Pedersen K R, Crane P R, Friis E M. Pollen organs and seeds with Eucommiidites pollen. Grana, 1989, 28: 279-294

39 Tekleva M V, Krassilov V A. Comparative pollen morphology and ultrastructure of modern and fossil gnetophytes. Rev Palaeobot Palyn, 2009, 156: 130-138

40 Yang Y. Asymmetrical development of biovulate cones resulting in uniovulate cones in Ephedra rhytiodosperma (Ephedraceae). Plant Syst Evol, 2007, 264: 175-182

41 Fürsich F T, Sha J, Jiang B, et al. High resolution palaeoecological and taphonomic analysis of Early Cretaceous lake biota, western Liaoning (NE-China). Palaeogeogr Palaeoclimatol Palaeoecol, 2007, 253: 434—457

42 Li Y, Sha J, Wang Q, et al. Lacustrine tempestite litho- and biofacies in the Lower Cretaceous Yixian Formation, Beipiao, western Liaoning, northeast China. Cret Res, 2007, 28: 194-198

43 邢德和, 孙春林, 孙跃武, 等. 义县组研究的新认识. 地球学报, 2005, 26: 25-30

44 张立军, 巩恩普, 徐德亮, 等. 辽宁北票四合屯盆地下白严地下白垩统义县组沉积相. 古地球学报, 2005, 7: 70一78 